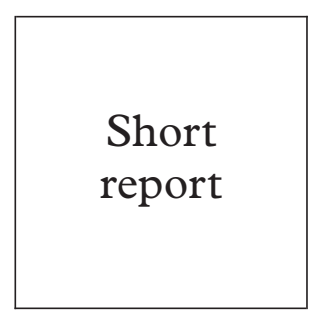

\title{
Attendance by older patients at a genitourinary medicine clinic
}

\author{
J M Tobin, V Harindra
}

Objectives: To determine how patients aged 50 and above had been referred to a department of genitourinary medicine (GUM), why they had attended, their sexual histories, and what diagnoses were made. To identify any special sexual health needs in this group of patients.

Methods: A case note review was undertaken of all patients aged 50 and over attending the Portsmouth GUM department over a 3 month period.

Results: There was a marked difference in reason for attendance between men and women in this older age group. Men were more likely to attend for a sexual health screen, often with minimal or no symptoms, following an extramarital or casual liaison. Women more commonly had symptoms causing difficulties with sexual intercourse with their regular partner.

Conclusions: Older people present to GUM departments with a wide range of sexually associated problems. The diagnostic and management expertise available in GUM departments makes them ideal providers of sexual health care for this as well as younger age groups.

(Sex Transm Inf 2001;77:289-291)

Keywords: older people; sexual health; genitourinary medicine

\section{Introduction}

The Department of Health is currently developing a national integrated sexual health strategy $^{1}$ and quotes research identifying a number of risk factors and groups particularly vulnerable to the physical and psychological outcomes of sexual activity. These include young people under the age of 16 and men and women aged between 16 and 30. Problems highlighted are those of pregnancy and sexually transmitted infection (STI).

Genitourinary medicine (GUM) departments predominantly target these groups but are attended also by many older people. Very little is known about the sexual practices, needs, and problems of men and women over the age of 50 in the United Kingdom and a literature search revealed that this group is often specifically excluded from studies or data collection.

The British National Survey of Sexual Attitudes and Lifestyles undertaken by Johnson et al in 1990-1 ${ }^{2}$ aimed to quantify components of sexual history in a representative sample of the British population but took 59 as its upper age limit. However, the KC60 forms ${ }^{3}$ completed by GUM clinics, which provide the most comprehensive set of data on STIs in England, do record age groups for selected conditions and age at HIV diagnosis is also available. ${ }^{4}$

This study was undertaken to discover why older patients came to the Portsmouth GUM department and to identify their specific needs.

\section{Methods}

All patients, both male and female, aged 50 and over attending the Portsmouth GUM department as new or rebooked patients from 1 January 1999 to 31 March 1999 were included in the study. Case notes were reviewed on the day of each attendance and again at the end of the study period for demographic and clinical details. Data collected were those routinely recorded during patient consultations.

\section{Results}

During the 3 month study period 8\% (219/ 2622) of new or rebooked patients were aged 50 and above. The age range of the 95 men was 50-82 years (mean 59, median 57 years) and of the 124 women $50-85$ years (mean 58, median 56 years).

Referral by their general practitioner (GP) accounted for the attendance of $30(32 \%)$ men and $51(41 \%)$ women. Of the remaining men, $52(55 \%)$ had self referred, five $(5 \%)$ had been referred by other hospital departments, five ( $5 \%$ ) had been asked to attend by a partner, and three $(3 \%)$ had been seen initially at a gay men's community health project. Forty eight $(39 \%)$ of the women had referred themselves, $23(18.5 \%)$ had been advised to attend by hospital departments and local family planning clinics, and two (1.5\%) had been asked by a partner. Eighty eight (93\%) men and 121 (98\%) women agreed to be contacted by letter, telephone, or via their GP if necessary.

The self declared marital status of the men and women attending showed that twice as many women $(78 \%)$ as men $(36 \%)$ were in a stable (married or cohabiting) relationship. Only three $(2 \%)$ women identified themselves as single and among the 26 single men 23 reported that they were homosexual. Patients were asked how long they had been with their present partner and the length of time since they had last had sex. Of the women $99(80 \%)$ had been with their partner for between 10 and 50 years compared with $41(43 \%)$ of the men. Slightly more women, 59 (48\%), than men, 43 (45\%), had had sex within 1 month of their clinic attendance and fewer women, 10 (8\%), compared with men, $16(17 \%)$, had not had sex for more than 5 years. One woman had never had sex and details were not recorded in 


\section{Key messages}

- Older people present to GUM departments with a wide range of sexually associated problems.

- Genital symptoms do not differentiate between STIs and other pathology_-best management requires accurate diagnosis.

- Compared with younger age groups older people are more likely to present with genital dermatological and hormone related problems than STIs.

- GUM departments are ideally suited to diagnose and manage sexual health problems in older people. the notes of six women and two men. Extramarital sexual contact (EMC) in the past year was admitted by $11(12 \%)$ men and three $(2 \%)$ women although one woman who had been sexually assaulted abroad 15 years previously identified this as her reason for attendance.

Thirty $(24 \%)$ women had undergone hysterectomy and 66 (53\%) were postmenopausal. Hormone replacement therapy (HRT) had been used by $71(57 \%)$ at some time with 54 (44\%) current users.

The single main reason given by each patient for attending the clinic is shown in table 1 . In this study presenting symptoms possibly suggesting an STI were considered to be urethral discharge in men and warts or genital ulceration in both men and women. A sexual health screen or HIV test was requested by $23 \%$ of the men compared with $3 \%$ of the women.

No women but three men declined a full sexual health screen although this was not undertaken in $26(21 \%)$ women and $22(23 \%)$ men in whom there was considered to be no clinical indication

Table 2 shows the main diagnosis made in each patient. An STI was diagnosed in 17 men $(18 \%)$ but only three women (2\%). Fifty two of the 124 women ( $42 \%)$ were diagnosed as having atrophic vulvovaginitis. This included some women using HRT for menopausal symptoms.

Table 1 Symptoms or reasons for attendance

\begin{tabular}{lcc}
\hline & Men & Women \\
\hline Genital soreness & $24(25 \%)$ & $84(68 \%)$ \\
Symptoms STI & $19(20 \%)$ & $12(10 \%)$ \\
Check up & $12(13 \%)$ & $3(2 \%)$ \\
HIV test & $10(10 \%)$ & $1(<1 \%)$ \\
Known HIV positive & $11(12 \%)$ & $1(<1 \%)$ \\
STI contact & $4(4 \%)$ & $1(<1 \%)$ \\
Sharps hotline & $3(3 \%)$ & $2(1.5 \%)$ \\
Menopausal problems & $-14(11 \%)$ \\
Other & $12(13 \%)$ & $6(5 \%)$ \\
Total & 95 & 124 \\
\hline
\end{tabular}

Table 2 Main diagnoses made

\begin{tabular}{lrlr}
\hline Men & \multicolumn{3}{l}{ Women } \\
\hline Balanitis & 8 & Atrophic vulvovaginitis & 52 \\
NSU & 7 & Vulval eczema & 15 \\
Lichen sclerosis & 4 & Acute candidiasis & 12 \\
Zoon's balanitis & 4 & Chronic candidiasis & 4 \\
Chlamydia & 3 & Lichen sclerosis & 7 \\
Warts & 3 & Warts & 2 \\
Herpes & 3 & Herpes & 1 \\
Other & 22 & Other & 17 \\
None & 40 & None & 14 \\
HIV & 1 & HIV & 0 \\
Total & 95 & Total & 124 \\
\hline
\end{tabular}

Another 38 had a vulval dermatosis or candidiasis.

All cases of lichen sclerosis and Zoon's balanitis were confirmed by biopsy.

\section{Discussion}

During the study period $14.8 \%$ of men and women attending the Portsmouth GUM department were referred by their GP or another health professional, but of the older age group $32 \%$ of men and $42 \%$ women were referred. Sexual health promotion targeting the younger population may account for their greater awareness of GUM services and increased rate of self referral but it is of interest that even when self referred our older patients did not appear to be anxious about confidentiality.

Although only $18 \%$ men and $2.4 \%$ women in this study had a STI the majority had genital symptoms. As such symptoms do not differentiate between STIs and other genital pathology accurate diagnosis is required to allow effective treatment and best management. Our STI figures are lower than those reported by Jaleel et $a 1^{5}$ and Cranston and Thin ${ }^{6}$ who reported 31\% and $27 \%$ respectively in their studies of elderly patients. However, more of our patients were women in long term stable relationships and many of them had oestrogen deficient vulvovaginitis, sometimes despite systemic HRT, accounting for sexual problems with their regular partner. In the Portsmouth GUM department we prescribe systemic and/or local HRT as appropriate for these women until their symptoms resolve when they return to primary care. Compared with younger age groups STIs have a lesser role in the sexual health of older people ${ }^{3}$ who often present with hormone related problems and genital dermatology. First diagnosis of HIV is unusual over the age of $60^{4}$ but with improving treatments more infected people will survive to become elderly. As long ago as 1993 Age Concern ${ }^{7}$ thought that older people were neglected by health educators, overlooked by health workers, and could be excluded from HIV related service provision and it will be important for the sexual health strategy to address these issues. Cranston and $\mathrm{Thin}^{8}$ recommended that older people should be encouraged to attend GUM services by making these accessible, sensitive, and welcoming. This will become increasingly important as continuing sexual activity after the reproductive years is made easier by HRT for women and erectile dysfunction treatments for men. Johnson et $a l^{2}$ found that partner availability strongly influenced the frequency of sex and was highest in those either married or cohabiting although sex became less frequent as the length of the relationship increased. In a 1988 study of sexual interest and behaviour ${ }^{9} 62 \%$ men and 30\% women aged 80-102 were still having sex.

The findings of our study suggest that, in Portsmouth, older men and women attend GUM departments for different reasons. Most women come for accurate diagnosis of genital problems causing difficulties with sex in long term relationships. Many men attend because of concerns following casual sex or EMC and 
have a higher risk of an STI. The skills found in GUM departments are ideally suited to diagnose and manage sexual health problems in this age group.

Contributors: JMT had the initial idea for this study, collected and analysed the data, and wrote the paper; VH contributed patients to the study and assisted with the analysis and writing of the paper.

There are no conflicts of interest.

1 Developing a sexual health strategy. London: DoH 1999. www.doh.gov.uk/sexualhealth.htm

2 Johnson AM. Wadsworth J. Wellings K, et al. Sexual attitudes and lifestyles. London: Blackwell Scientific Publications, 1994.
3 Hughes G, Simms I, Rogers PA, et al. New cases seen at genitourinary medicine clinics: England 1997. CDR Suppl 1998;8:7.

4 AIDS and HIV Infection in the United Kingdom: monthly report. Commun Dis Rep 1998;8:191-2.

5 Jaleel H, Allan PS, Wade AAH. Sexually transmitted infections in elderly people. Sex Transm Inf 1999;75:449.

6 Cranston RD, Thin RN. How common are sexually Cranston RD, Thin RN. How common are sexually
transmitted infections in the elderly. Sex Transm Inf transmitted infe

7 Age Concern. A crisis of silence: HIV, AIDS and older people. London: Age Concern, June 1993.

8 Cranston RD, Thin RN. Sexually transmitted infection in the elderly. Sex Transm Inf 1998;74:314-5.

9 Bretschneider JG, McCoy NL. Sexual interest and behaviour in healthy 80-102 year olds. Arch Sex Behav 1998;17: $109-29$.

\section{Clapham omnibus}

There was no turning back. Our long suffering medical secretary had sold her property and was looking forward to her retirement in Spain. She had previously worked in the medical school as a senior administrator and treated us like medical students. She was robust, ultra organised, and a trusted member of staff. The time had come to find her replacement.

The CVs from the short listed applicants were satisfactory. Some had previously worked in the NHS, others had worked as medical secretaries, and all had some experience with word processing. With the interviews over, it was crunch time-the audiotyping test. Like the unseen passage of music that is used in music examinations, this was to be the test that would separate the wheat from the chaff. Or so we thought. The excerpt below is a true account of one candidate's attempt:

"Thanking for sending this young lady to the clinic. She was ansthematic but aware that when you took her vital cytology, we noticed a heavy thick offensive yellow virginal discharge and contact bleeding of the cervix. She was taking the oral contraceptive pill.

On examination, she had no sign of vulgar patronises. She had, however, a heavy puriland froffy offensive virginal discharge. The cervix showed an irregular lesion on the posterior aspect of the arse possibly arsoration. She had no other signs. Her grand stain smear showed an inflammatory picture.

In view of her signs and symptoms gram stains smear, we treated her protem with doxicyci $106 \mathrm{~g}$ BD for seven days with metroidrocel $400 \mathrm{mg}$ BD for five days. Her clamidayia EIA has actually concerned prodemial infection. We are awaiting her conacockel culture result. I will keep you informed.

Yours sincerely"

Is it any wonder that laughter is (still) the best medicine? 